\title{
A cosmopolítica do Consenso de Washington e as indústrias culturais na América Latina
}

Sebastião Guilherme Albano da Costa* Maria Érica de Oliveira Lima**

Resumo: 0 texto descreve as formações discursivas na sociedade latino-americana desde 0 Consenso de Washington até nossos dias e suas implicações nas indústrias culturais nacionais. Integram-se dois blocos de proposiçoes. Um está adscrito à categoria de "cosmopolítica" e os modelos de atuação política e econômica relacionados com instâncias de produção e reprodução midiática e as sensibilidades contemporâneas. 0 segundo é norteado pela reflexão sobre o cinema e a virtualização da América Latina, reorganização das instituições e identidades em face da emergência de parâmetros de reconhecimento em que os signos condicionados aos cronotopos nacionais se aclimataram aos padrões cognitivos das novas mídias.

Palavras chave: Cosmopolítica, Consenso de Washington, Mídia, Virtualização da América Latina.

RESUMEN: En este texto se describen las formaciones discursivas de las sociedades latinoamericanas a partir del Consenso de Washington hasta los primeros años del presente siglo y sus implicaciones en las industrias culturales. Integramos dos bloques de proposiciones. Uno adscrito a la categoría de "cosmopolítica" y sus modelos de actuación política y económica en instancias de producción y reproducción mediática y sus vínculos con las sensibilidades contemporáneas. El segundo, reflexiona sobre el cine y la virtua-

Centro de Ciências Humanas, Letras e Artes de la Universidade Federal do Rio Grande do Norte, Brasil (sgac@ufrnet.br).

* Centro de Ciências Humanas, Letras e Artes de la Universidade Federal do Rio Grande do Norte, Brasil (merical@yahoo.com.br). 
lización de América Latina, la reorganización de instituciones e identidades vinculadas a los parámetros de reconocimiento de los signos nacionales, los cuales tuvieron que adaptarse a nuevos patrones.

Palabras Clave: Cosmopolítica, Consenso de Washington, Medios, Virtualización de Latinoamérica.

ABSTRACT: This text describes the rising of discursive forms in Latin American society since the Washington Consensus until today and their implications on the national cultural industries field. The first section is related to "cosmopolitics" category and tries to reveal economic and political models of actions and their connections with contemporary sensibilities. The second is focused on debates about the cinema and virtualization of Latin American, a reorganization of institutions and identities that surpass a former system of representation based on national cronotopos and seek to achieve new media cognitive patterns.

Key words: Cosmopolitics, Washington Consensus, Media, Virtualization of Latin America. 


\section{INTRODUÇÃO}

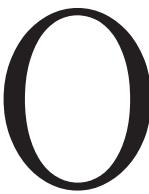

intuito deste estudo é apresentar um quadro das grandes formações discursivas advindas na sociedade latino-americana a partir do que se convencionou denominar o Consenso de Washington até nossos dias e suas implicações no âmbito das indústrias culturais nacionais. Para esse fim, buscou-se integrar dois blocos de proposições que serão apresentados conjuntamente. O primeiro está embasado na categoria de "cosmopolítica", 1 um neologismo já registrado no debate norte-americano sobre os modelos de atuação política e econômica e seus vínculos com as sensibilidades contemporâneas, mas aqui circunscrito a certos níveis de produ ção e reprodução midiática. O segundo bloco será norteado pela reflexão sobre a mídia e o que será referido como a virtualização da América Latina, a saber, um processo de reorganização das instituições e das identidades regionais em face da emergência de parâmetros de reconhecimento em que os signos e a verossimilhança condicionados aos cronotopos (históricos e geográficos) locais, tão caros aos modos de representação desde o século xIx, tiveram de se aclimatar aos padrões cognitivos surgidos com as novas mídias. Tratar-se-ão desde a imigração física até a imigração do gosto, bem como das novas estruturas de fomento e produção cultural até as modalidades de consumo e reprodução simbólica.

Isso posto, cumpre aclarar também que ao mencionar cosmopolítica faz-se alusão ao momento em que políticas nacionalistas foram implementadas em todos os quadrantes da América Latina por suas elites a fim de que se constituíssem os estados nacionais e participassem do concerto internacional, o que foi nomeado por Immanuel Wallerstein de sistema-mundo ${ }^{2}$ ou universalismo europeu, ${ }^{3}$ e arriscaríamos ironizar referindo-nos a uma universalização da nacio-

1 Pheng Cheah y Bruce Robbins [orgs.], Cosmopilitics. Thinking and Feeling beyond the Nation, Minneapolis, University of Minnesota Press, 1998.

2 Immanuel Wallerstein, Modern World-System: Capitalism, Agriculture and the Origins of the European World-Economy in the Sixteenth Century, Nueva York, Academic Press, 1981.

3 Immanuel Wallerstein, O Universalismo europeu. A retórica do poder, trad. de Beatriz Medina, São Paulo, Boitempo, 2007. 
nalidade. Convém recordar que o predicado cosmopolita é anterior à criação dos estados nacionais, portanto precede à noção de nacionalismo, e em princípio encerra sentidos mais progressistas se observado da perspectiva dos direitos e dos deveres do cidadão, isto é, quando se lhe contempla o arco de enunciados que dão conta das relações em sociedades com alto grau de complexidade. Mas no plano das representações midiáticas a questão se torna um pouco mais intrincada.

Remete-se ainda ao fato de tais programas nacionalistas, ao menos os que concernem à representação (mimese) literária ou midiática e sua ilusão de referência do local, perderem sua feição pedagógica e estratégica, de indução de uma só identidade nacional, e afirmarem-se como globais a partir do último quartel do século xx, devido talvez às diretrizes do Consenso de Washington. Concatena-se ainda cosmopolítica com as discussões atuais sobre a necessidade de formulação de marcos regulatórios para práticas sociais que vão além dos limites nacionais, inclusive aquelas que concernem à produção e recepção de conteúdo simbólico. Consideram-se as representações como práticas sociais e o regime de representações atual, do qual será aludido o projetado pelo cinema regional nos últimos 20 anos, corresponde a um tipo de cultura que se pode considerar global.

No que tange à reflexão sobre a mídia e o termo de virtualização da América Latina, descrever-se-á o crescente desempenho dos meios na validação dos sentidos que circundam as práticas sociais e sua inflexão na região, onde o espaço público burguês esboçado no século xIX, embasado nos meios impressos e mormente no jornalismo, contou com uma comunidade interpretativa reduzida e engajada e, em contrapartida, o espaço público multimidiático contemporâneo já parece coadunar, em potência, com o gosto e as habilidades intelectivas de parcelas mais amplas da população. Seu escopo remonta à emergência da democracia partidária em âmbito político no século xIx junto com o jornalismo de massa e, no século xx, aos fluxos econômicos transnacionais e às modalidades eletrônicas e digitais de poiesis e comunicação e sua codificação em plataformas determinadas para a veiculação imediata e a grandes audiências. O cerne dessa vértebra do estudo tem origem na própria denominação América Latina, uma 
noção etérea que ganhou corpo a partir de seu registro nas atas da geopolítica do dezenove europeu e na atualidade parece desencarnar em razão de inúmeros processos do que se habitou chamar desterritorialização: do capital, das pessoas em relação a seus lugares de origem e, principalmente, dos novos meios de informação e comunicação que atuam em uma ambiência virtual. ${ }^{4}$

\section{Cosmopolítica}

A mundialização da ideia de multiculturalismo no plano das políticas públicas apenas em aparência chancela a fórmula mais figurada que factual de compreensão do outro por via da miscigenação inventada pelos pensadores cosmopolitas, liberais e criollos do século XIX na América Latina, leitores de Jean Jacques Rousseau, e radicalizada por seus epígonos ideologicamente mais complexos do século xx, tais como José Vasconcelos, José Carlos Mariátegui, Fernando Ortiz e Gilberto Freyre. Entre nós o que foi tomado como uma política de nacionalização progressista (miscigenação) e valorização das raças, etnias e costumes locais, isto é, uma política de identidades fortes mas híbridas, foi se resvalando a acepções associadas ao multiculturalismo, e não a políticas de identidades heteroglóssicas, ou políticas heteroglóssicas de identidade, consubstanciadas, talvez, na categoria de cosmopolítica. Com efeito, o multiculturalismo funciona como um eufemismo asséptico baseado no gosto burguês pelo exótico no campo do entretenimento e que, na economia política, revela uma nova divisão do trabalho e um novo tipo de segregação. De outro lado, mas não contraditoriamente, manifesta ainda o pendor à convergência superficial de valores no capitalismo que "transforma as atividades sociais em propriedade". 5

Dois exemplos da operacionalidade do multiculturalismo no esquema liberal contemporâneo podem ser apontados no nosso continente. O primeiro corresponde à inexistência de uma cláusula que aluda à permissão da circulação

4 Jonathan Bignell, Postmodern Media Culture, Edinburg, Edinburg University Press, 2000.

5 George Yúdice, "La globalización y la nueva división internacional de trabajo cultural", en Mónica Lacarrieu y Marcelo Álvarez [comps.], La (indi) gestión cultural. Una cartografía de los procesos culturales contemporáneos, Buenos Aires, Ciccus, 2002, p. 21. 
de pessoas no documento fundador do Tratado de Livre Comércio da América do Norte (TLCAN) entre o México, os Estados Unidos e o Canadá, com vigência a partir de 1994, sendo que há cerca de 12 milhões de mexicanos ilegais no país vizinho. O outro se refere à pouca circulação de produtos das indústrias culturais de outros países nos Estados Unidos, notadamente de filmes para o cinema. Naquele mercado, mais de $90 \%$ das obras que estréiam em cinemas são reali zadas lá mesmo, ou ao menos os direitos são registrados por empresas nacionais.

Desde logo não compartilhamos da ideia altissonante de que a política hoje é a política da mídia, feita por e para a mídia. ${ }^{6}$ Mas tampouco nos furtamos ao fato de que, alcançada uma tal influência, os meios colaboram para apresentar e orientar o espaço público em que se encenam os contenciosos de interesse comum, seja no plano local ou global. Em todo caso, percebe-se que esses meios têm se desempenhado como instrumentos de práticas sociais sob condições jurídicas cujas premissas são a propriedade intelectual e o copyright, dois tropos espaciais propagados pela Organização Mundial do Comércio (OMC) como uma rubrica cada vez mais requisitada na economia. Nesse sistema de contradições, em que convivem desterritorização, propriedade e virtualização, o entendimento de cosmopolítica na América Latina está norteado pela

[...] transformação dos sistemas de comunicação mediante processos neoliberais (privatização, desregulamentação, eliminação de serviços proporcionados pelo Estado de bem-estar por razões políticas e econômicas) resulta em uma recomposição e ressignificação dos territórios e públicos. A transnacionalização e (neo) liberalização das indústrias culturais impõem (1) a necessidade de inserir-se em uma economia supracional e (2) reestruturações que facilitem essa inserção, respondendo a "uma dialética da uniformização e da diferenciação" 7

A máquina de argumentação moderna e liberal processa a heterodoxia em convergência e, nesse caso, sua inversão resulta em um sofisma que apenas se desvela quando se percebe que a obtenção dos lucros das empresas transna cionais, emblemas da globalização desterritorializada, derivam da posse de

Manuel Castells, Communication Power, Oxford, Oxford University Press, 2009, p. 320.

Yúdice, op. cit., pp. 21 y 22 (traducción nuestra). 
direitos de propriedade onde antes era bem público e da denominação de bem público universal ao que antes era próprio dos estados-nacionais. Talvez essa seja uma nova forma de espacialização, o que David Harvey chama de espaços do capitalismo global. ${ }^{8}$ Não há uma nota moral na asserção anterior, seu perfil sentencioso corresponde apenas à surpresa pela constatação de um dado. Já em 2002, cerca de 12\% do Produto Interno Bruto dos Estados Unidos provinha da criação de tal modalidade de patrimônio, a propriedade intelectual. ${ }^{9}$

Para aclarar o âmbito em que uma cosmopolítica é aplicada, cabe o comentário de Bruce Robbins sobre o caráter culturalista do termo, ${ }^{10}$ sem a inflexão pejorativa. Em tal situação, pode-se afirmar que as políticas culturais hoje não são prerrogativas apenas dos Estados, a despeito desses seguirem como poderosos reguladores de identidades, mas se manifestam cifradas em atitudes grupais politizadas em favor do reconhecimento de signos não identificados, ao menos da maneira em que nos ensinaram, com a nação projetada tão somente pelo território, pelo vernáculo e pela população. As marcas da nacionalidade, que permanecem no idioma ou no sotaque, nos costumes representados etc., transitam agora cifrados em instâncias que se dizem intangíveis, como a sensibilidade, o gosto e as trocas simbólicas que decorrem da imigração física e do gosto, da recepção e da utilização dos gadgets, dos produtos audiovisuais e de outras textualidades multimidiáticas, principal-mente as que a tecnologia digital propicia, e nesse sentido aparecem na produção e no consumo de bens da cultura global.

Há mais de 20 anos, durante a transição argentina à democracia, Óscar Landi já apontava em seu comentário ao Plano Nacional de Cultura (1984-1989), que

8 David Harvey, Spaces of Global Capitalism: Towards a Theory of Uneven Geographical Development, Londres, Verso, 2006.

9 Enrique Sánchez Ruiz, "La industria cinematográfica del TLCAN: del 'mercado libre' a las políticas públicas", en Néstor García Canclini, Ana Rosas Mantecón, Enrique Sánchez Ruiz [coords.], Situación actual y perspectivas de la industria cinematográfica en México y en el extranjero, Guadalajara, Universidad de Guadalajara/Instituto Mexicano de Cinematografía, 2006, p. 21.

${ }^{10}$ Bruce Robbins, Feeling Global. Internationalism in Distress, Nueva York/Londres, New York University Press, 1999. 
"O estado está distante de ser um desejado centro irradiador de sentido à cotidianidade, ao trabalho e à criação artística e científica" e, parafraseando o mesmo documento, exorta à "instauração de uma nova ordem da comunicação e da informação", que talvez tenha a mesma importância relativa "que os debates e decisões sobre o sistema educativo de fins do século passado". " ${ }^{11}$ Em meados do decênio de 1980 já se advertia uma nova sensibilidade que fazia convergir a ordem econômica hegemônica, as limitações políticas e os deslocamentos dos paradigmas culturais. Portanto, hoje se consideram agentes de cosmopolíticas a esses grupos ou comunidades interpretativas ${ }^{12}$ porquanto compõem novas esferas públicas cuja espacialidade e as marcas referenciais navegam em imagi nários transnacionais e em ambientes virtuais que suscitam experiências de cunho intercultural.

De qualquer maneira, quando observamos as características de intervenção de grande parte dos latino-americanos nesses meios o ideário composto pelas políticas nacionalistas e que resultou em ensaios, romances, filmes, música, teatro e artes plásticas com acentuada cor local, ou ao menos em um determinado sistema de representações regionais, não parece ter sido de todo aplacado pela entrada de novos atores e novas racionalidades ao drama da história. Sobrevivem figuras de contestação junto a certo miserabilismo populista, ${ }^{13}$ mesmo nas esferas discursivas que permitem, além da representação, uma simulação digital das identidades e uma narratividade interativa e em tempo real. Essas atividades são realizadas em uma chave de entretenimento que de algum modo dissimula a raiz econômica de suas propostas intelectivas e esté ticas, a ponto de não percebermos que estamos consumindo um produto, o

11 Óscar Landi, "Campo cultural y democratización en Argentina”, en Néstor García Canclini, Políticas culturales en América Latina, México, Grijalbo, 1987, pp. 147-163 (traducción nuestra).

12 Janice A. Radway, Reading the Romance. Women, Patriarchy, and Popular Literature, Chapel Hill/Londres, The University of North Caroline Press, 1991.

13 Claude Grignon y Jean Claude Passeron, Lo culto y lo popular. Miserabilismo y populismo en sociología y en literatura, trad. de María Sonderéguer, Buenos Aires, Nueva Visión, 1991. 
resultado de uma produção ${ }^{14}$ seja quando se usa a rede, por exemplo, apenas como dispositivo de comunicação ou informação ou quando se lhe utiliza como meio de pesquisa ou de suporte para realização artística. Mary Douglas e Baron Isherwood anotavam já há mais de 30 anos em 0 mundo dos bens, 1979, que o consumo torna a cultura visível e estável. ${ }^{15}$

Mesmo assim, na América Latina as instâncias de produção de sentido e validação social que as novas comunidades ativam mediante o consumo consubstanciam uma espécie de projeto político inconsciente, ${ }^{16}$ de vez que muitas dessas expressões tendem a ser alternativas (pirataria, trabalho informal, vindicação de direitos sociais) e parecem ir de encontro à razão mercadológica da sociedade da informação, malgrado não haja temas impertinentes para os meios, cujos parâmetros discursivos, mais ainda ao abrigo dos postulados do Consenso de Washington, naturalizam sem delongas quase toda dissidência. Campeiam na rede sites de associações políticas sem que, até agora, haja uma pronta resposta social para seus argumentos, salvo no teatro virtual de ações, onde comunidades se conectam para intercambiar experiências, entre outras exceções.

Certamente hiperbólicas, as conjeturas contemporâneas acerca dos atributos que os meios de comunicação possuem, sejam tradicionais ou novos, e sua ingerência na caracterização das identidades e das subjetividades na chamada sociedade da informação é uma tendência que medrou primeiro como teoria sobre o influxo da técnica sobre o sujeito na sociedade de massas (Innis; McLuhan; Baudrillard $)^{17}$ e tem uma precedência extensa que sem muito esforço nos levaria primeiro à arte retórica da Idade Média e talvez até aos sofistas. A limitação das

14 Harvey, op. cit.

15 Mary Douglas, Baron Isherwood, The World of Goods. Towards an Antrbropology of Consuption, Londres/Nueva York, Routledge, 1996, p. 38.

${ }^{16}$ Frederic Jameson, "Notes on Globalization as a Philosophical Issue", en Fredric Jameson, Masao Miyoshi [eds.], The Cultures of Globalization, Durhan, North Carolina, Duke University Press, 1998 , pp. 38-75.

${ }^{17}$ Harold Innis, The Bias of Communication, Toronto, University of Toronto Press, 1999; Marshal McLuhan, Understanding the Media: The extensions of Man, Massachussets, MIT, 1994; Jean Baudrillard, Xerox and Infinity, trad. de Agitac, Londres, Touchepas, 1988. 
trocas humanas ao que logra ser informado nos parâmetros da técnica tem algo de determinista, bem como o tem a submissão do intercâmbio simbólico ao mercado capitalista e da experiência do poder às relações de classe. Ao mesmo tempo, nenhuma dessas simplificações é de todo impertinente, como já o demonstrou o estudo de Benedict Anderson Comunidades imaginadas cuja tese central sobre a invenção das nações, ao menos em sua versão difundida pelo discurso da imprensa, pode ser contestada.

Evita-se portanto aqui uma reflexão unilateral que neste caso equivaleria a consignar, por exemplo, a cosmopolítica à economia política dos meios antes que a uma administração progressista de valores locais e nacionais e de negociação entre esses e uma ordem global. Para contornar essa propensão sentenciosa que extrai verdades ao que se observa mediante uma lente epistemológica determinada, trataremos de levantar uma série de questões sobre o desempenho dos meios nos processos sociais que permearam e permeiam o debate público e enfatizaremos uma discussão a partir de sua atuação em uma dinâmica multidimensional, não como estrutura autônoma de criação de signos que ditem as relações sociais sob o pretexto de representá-las, e sim que indiquem a interdependência entre os fatores que compõem a sociedade. A finalidade é enfeixar e refletir sobre dados relativos ao advento dos valores que propiciaram uma cultura ou civilização das mídias e sua manifestação no que se tem convencionado chamar de sociabilidades contemporâneas. ${ }^{18}$

\section{Mídia E VIRTUALIZAÇÃO DA AMÉRICA LATINA}

É certo que há uma influência crescente dos meios como legitimadores dos vínculos sociais, notadamente no que concerne à figuração de uma nação tangível, à configuração de identidades nacionais durante todo o Oitocentos até meados do século passado e à composição de identidades culturais na contemporanei-

18 Maurice Agulhon, Penitents et franc-maçons de l'ancienne Provence: essai sur la sociabilité méridionale, París, Fayard, 1968; François-Xavier Guerra, "A nação moderna: nova legitimidade e velhas identidades", en Istvan Jancsó [org.], Formação do Estado e da nação, São Paulo, Hucitec, 2003; Marco Morel, As tranformações dos espaços públicos. Imprensa, atores políticos e sociabilidades na Cidade Imperial (1820-1840), São Paulo, Hucitec, 2003. 
dade. Noções como política, sociedade, espaço público, constituição e Estado nacional, novidades que ascenderam com a Revolução francesa e penetraram no vocabulário utilizado para o debate sobre as relações humanas em comunidade, mantêm proximidade com o avanço das técnicas de registro e emissão de conteúdos, algo sugerido na expressão capitalismo impresso cunhada por Benedict Anderson para o papel da imprensa na legitimação do formato social. Articulados como mensagens em um discurso que dilui sua proposição específica, esses conceitos se projetam até a atualidade e compõem parte dos pilares em que está sustentada nossa percepção da realidade social, apresentando-se naturalizados e, como diz Roland Barthes, despolitizados. ${ }^{19}$

A renovação contínua dos modos de elaboração e de circulação das inter subjetividades levou a que os suportes técnicos que realizam a tarefa didática de ensinar a civilidade adquirissem o estatuto de processadores de enunciados econômicos, políticos e culturais e ganhassem ampla ascendência social, em substituição às instituições do Estado. Assim, a dependência da cidadania contemporânea ao manejo das ferramentas técnicas da comunicação mediada e ao acesso a seus conteúdos desestabiliza o paradigma anterior em que boa parte das decisões de ordem civilizadora, do instituto dos parâmetros do gosto coletivo (as iconografias nacionalistas) às organizações corporativas (sindicatos) e mesmo à inclusão ao mundo do saber e do trabalho (conteúdos escolares, inscrições nos centros de ensino, busca por emprego), parecia estar em mãos do Estado.

Esse perfil era ainda mais acentuado no caso da América Latina, em que o Estado surgiu antes que a nação e forjou-se a si mesmo, à força mais de posições autoritárias do que de fomento a instituições modernas sólidas, o mito de Estado forte. Tal como os jornais do século xIX começaram de pronto a utilizar peças novas no vocabulário, como vimos (constituição, pátria, nação etc.), dissemi nando a reflexão sobre esses temas, hoje tópicos políticos e econômicos tais como a globalização, o multiculturalismo, a tolerância com as chamadas diferenças, a ecologia, os direitos humanos etc., povoam a imaginação dos publicitários,

19 Roland Barthes, Mitologias, trad. de Rita Buongermino y Pedro de Souza, Rio de Janeiro, Bertrand, 1993. 
dos produtores de contéudo dos jornais, dos programas de televisão, dos filmes de cinema e dos sites da Internet.

Essa convergência de narrativas é possibilitada pelas estruturas discursivas das plataformas midiáticas, que operam sob protocolos comuns em qualquer parte do planeta, não obstante a possível heterogeneidade dos conteúdos. Esse esforço pelo consenso da imaginação alcançado por intermédio de um padrão técnico de comunicação e informação não é um dado recente. Temos dedicado muita atenção às querelas entre Google (a empresa cujo lema é Não seja mau e hoje a maior corporação de mídia do mundo) e o governo chinês sobre o controle ao acesso de determinados temas no programa de buscas. O bloqueio inicial a consultas relacionadas com Taiwan, com os eventos da Praça de Tianamen ou com o Dalai Lama, todos sensíveis ao regime político daquele país, e a atual exortação à renegociação dos termos do contrato, explicitam a existência de atores econômicos (e políticos) globais que não são propriamente enquadrados no formato do Estado nacional. Convém repisar sobre o fato de que esse tipo de investidas não é novo.

Por exemplo, George Yúdice ${ }^{20}$ alerta para as opiniões recentes do Banco Mundial (BM) e a Organização Mundial do Comércio (OMC) nas políticas sobre o audiovisual na América Latina. Se recuarmos mais chegamos às ações do Escritório para Assuntos Interamericanos, entre 1940 e 1946, em mãos de Nelson Rockfeller, que cumpriu papel semelhante. Essa orientação à homogeneidade pode haver surgido em 1918 com a promulgação da lei Webb-Pomerene pelo Congresso norte-americano, que proibia os trusts de mídia dentro dos Estados Unidos, mas os fomentava em outros países. ${ }^{21}$

Essas mobilizações, de uma maneira ou de outra, dão conta de um estado de coisas em que a técnica de registro, transmissão e recepção de conteúdos (saberes, informação, dados numéricos etc.) é naturalizada, importando a partir de então a ordem de relação entre formatos de segundo grau, como os progra-

${ }^{20}$ Yúdice, op. cit., p. 20.

21 Tob Miller y Richard Maxwell, "Film and Globalization", en Olivier Boyd-Barret [ed.], Communications Media. Globalization and Empire, Eastleigh, Londres, John Libbey Publishing, 2006, p. 35 . 
mas, os conteúdo, o tipo de mensagens etc. Essa sinalização de homogeneidade cultural, como se a cultura fosse apenas cultura das mídias, resultou em diagnósticos peremptórios sobre o papel do Estado ou do Estado nacional na condução nas práticas associativas mais determinantes para as relações sociais contemporâneas. Néstor García Canclini atesta que as políticas culturais dos estados nacionais na América Latina não devem custodiar o patrimônio tradicional (artes plásticas, teatro, música, dança etc.), mas formular uma gestão clara para a indústria cultural que em sua opinião, parafraseando James Clifford, enfatizaria políticas pós-identitárias. Para Jesús Martín-Barbero, as novas mídias carecem de um status semelhante ao conferido aos serviços públicos, tais como a saúde e a educação. Para o antropólogo Gustavo Lins Ribeiro, "A estrutura dos sentimentos contemporânea' [...] é frequentemente baseada nos meios de comunicação [...]" (tradução nossa). ${ }^{22}$

As políticas voltadas para a ordenação dos meios de comunicação tradicionais, em especial no que tange à televisão, demonstram o mito do Estado forte na América Latina e a irrelevância das leis voltadas para sua normatização, o que talvez se reflita no diletantismo das instituições regionais em face do avanço das corporações midiáticas e a ausência de legislação atualizada. A despeito de as leis sempre destinarem aos meios como rádio e tv o estatuto de concessões públicas, seu desenvolvimento esteve antes em mãos de homens de negócios que do Estado, seguindo um padrão norte-americano de gestão, como atestam os inúmeros vínculos entre a Associação Interamericana de Radiodifusão (AIR, fundada em 1945) e a NBC e a CBS, afora sua inspiração nas diretrizes do Escritório de Assuntos Interamericanos.

Othon Jambeiro detalha que a criação do Departamento de Imprensa e Propaganda (DIP) em 1939 pelo regime do Estado Novo consolidou a censura à programação radiofônica, televisiva e mesmo cinematográfica e ao conteúdo dos jornais ao mesmo tempo em que instituía a obrigação de transmitir "uma ideologia nacionalista dedicada à construção de um capitalismo urbano-industrial [...] voltado

${ }^{22}$ Gustavo Lins Ribeiro, Pos-Imperialism. A Latin-American Cosmopolitics, Brasília, Universidade de Brasília, 2005, p. 10. 
para sua própria cultura e seus valores tradicionais". Em que pese essa roupagem autoritária e estatizante, os meios de comunicação de massa "têm sempre sido predominantemente controlados e operados por interesses privados. Sua sustentação financeira tem, portanto, se originado da venda de anúncios e patrocínio". ${ }^{23}$ Com efeito, na América Latina há um extenso rol de homens de negócios como fundadores das redes de televisão locais, como o cubano Goar Mestre e o mexicano Emilio Azcárraga. Ambos tornaram-se grandes empresários de mídia, o primeiro na Argentina e em outros países da América do Sul, e o segundo com a fundação da Televisa, no rádio em 1923, e na tv em 1951, e hoje com interesses na área de telefonia. O caso da Rede Globo foi mais ou menos assim:

O percurso da Rede Globo começou nos anos 50, quando no governo de Juscelino Kubitschek é concedido um canal ao grupo Roberto Marinho. Suas empresas congregavam o jornal O Globo, em circulação desde 1925, a Rio Gráfica Editora (produtora e distribuidora de revistas em quadrinhos, fotonovelas etc.) e a Rádio Globo, fundada em 1944. Mas é somente mais tarde que o canal de tv é ativado; em 1962 a emissora se associa ao grupo americanos Time-Life, que tinha interesse em estrategicamente ocupar espaço nos meios de comunicação da América Latina. O canal 4 (rj) começou a operar em 1965 e no ano seguinte a emissora penetra em São Paulo com a compra da tv Paulista. No entanto, é a partir de 1969, num processo conjunto de consolidação empresarial, ampliação da rede e conquista de audiência, que a Globo vai firmar sua posição no espaço audiovisual brasileiro. Com a implantação do sistema de telecomunicações da Embratel, sua rede televisiva se amplia passando a cobrir parcelas significativas do território nacional [...]. Em 1983 a Globo passa a utilizar o satélite Intelsat aumentando a confiabilidade de sua cobertura nacional. ${ }^{24}$

O Estado moderno (capitalista, liberal, burguês) urdiu teias de sentidos coletivos a fim de sustentar seus postulados que, por sua vez, ganham autonomia e se replicam em novas práticas significativas e sociabilidades. A função da mídia nos primórdios dessa universalização da forma Estado (capi-

${ }^{23}$ Othon Jambeiro, A tv no Brasil no século xx, Salvador, Universidade Federal da Bahia, 2001, pp. $22-44$.

${ }^{24}$ Renato Ortiz, Sílvia Borelli y José Ramos, Telenovela. História e produção, São Paulo, Brasiliense, 1991, p. 80. 
talista, liberal, burguês) parece ter sido sua representação mediante bases retóricas em que a verossimilhança remetia tanto a uma sublimação da realidade física como evocava recursos históricos de uma tradição representativa determinada, estabilizada no que se conhece como a tradição ocidental, muito embora esses esquemas políticos e estéticos tenham permeado sociedades tão díspares como a Índia. Arjun Appadurai inclusive formulou uma série de dimensões em que os povos não ocidentais absorvem os supostos estímulos da modernidade, tais como ethnoscapes, financescapes, mediascapes e ideoscapes. ${ }^{25}$ Os meios, orientados por diretrizes capitalistas, operaram um processo de internacionalização já anunciado por Marx e Engels em 1848, quando disseram que a expansão de mercados é inerente às práticas capitalistas.

Sob essas condições, pode-se dizer que o Estado moderno tanto cultivou como se tornou objeto de representação, alusão, evocação direta ou indireta dessas textualidades. Nesse processo de mitificação necessária para naturalizar essa tradição representativa e seus suportes discursivos, criou-se a impressão de indiferenciação das classes (outro fator integrante desse sistema) e na atualidade divulga a máxima de tolerância racial, dos direitos humanos, do multiculturalismo etc., para que sua informação abarque o maior número de pessoas. Pode-se concluir que se ao princípio o Estado ainda se representasse na mídia, na atualidade é a mídia que se representa no Estado.

Na história universal a América Latina sempre foi objeto de miradas utópicas, basta consultar o repertório que, entre os mais proeminentes do século xx, estão La invención de América, publicado em 1958 pelo mexicano Edmundo O'Gorman, e Visão do paraíso publicado em 1959 por Sérgio Buarque de Holanda. Devido a nossa experiência de colonização, migrações, extermínio, tráfico de escravos etc., podíamos nos assemelhar aos territórios que James Clifford disse existir "apenas na ficção" ${ }^{26}$ As elites que construíram os estados nacionais mantinham uma atitude reflexiva em relação às instituições europeias,

25 Arjun Appadurai, Modernity at Large. Cultural dimensions of globalization, Minneapolis, Minnesota University Press, 1996, p. 37.

26 James Clifford, The Predicament of Culture. Twentieth-Century Ethnography, Literature, and Art, Cambridge/Massachusetts/Londres, Harvard University Press, 1988, p. 98. 
emulando com régua e compasso países como a França e mais recentemente os Estados Unidos. Chegou-se a adotar oficialmente as teorias positivistas e outras ciências que ao mesmo tempo em que defenestravam a escravidão faziam uma série de associações deletérias entre raça, clima e modernidade. No século xx, as guerras civis, os regimes militares e outros desvios ainda orientaram nossa história que, sem poder assimilá-los de todo, confrontou-se com novas séries de técnicas e valores que decidem a sensibilidade contemporânea. Denominamos essa transição como um período de virtualização da América Latina.

Nosso intuito aqui para finalizar é apontar um declínio dos modelos e dos motivos mais sólidos e já consagrados de representação da identidade nacional na América Latina. A inconstância e a volatilidade das instituições políticas e econômicas, em relação aos padrões ocidentais, e o apego à terra e às tradições, grandes topoi locais, estão em processo de reorganização em seus desempenhos como figuras descritivas da região. De fato, são inúmeros os elementos que ao menos em aparência estão em processo de desterritorialização ou de virtualização. Um dado importante a esse respeito foi o fenômeno das migrações e imigrações. O histórico regional motivou que parte da população latino-americana optasse pela saída de seus países, especialmente rumo à Espanha, aos Estados Unidos e ao Japão. De acordo com Marta Nubia Bello, ${ }^{27}$ que reproduz cifras até conservadoras e relativas a 2005, há mais de 650 mil latino-americanos na Espanha, sendo que os equatorianos e os colombianos representam a maior parte. Nos Estados Unidos, estimam-se 12 milhões de mexicanos ilegais. No Japão, cerca de 300 mil brasileiros buscam o sonho oriental.

É no plano das representações suscitadas pelas indústrias culturais que podemos medir o pulso desse processo. A Internet está crivada de sítios dos movimentos sociais mais destacados da região, tais como as páginas da Assam bleia Popular dos Povos de Oaxaca (asambleapopulardelospueblosdeoaxaca. blogspot.com), bem como a que nos enlaça com o Exército Zapatista de Libertação

${ }^{27}$ Nubia Bello, "Migración, redes sociales y ciudadanía. Aportes para la definición de políticas migratorias en Colombia, Ecuador y España", en Jesús-Martín Barbero, Guillermo Sunkel, Nubia Bello, Nina Pacari y José Manuel Vera, América Latina. Otras visiones desde la cultura, Bogotá, Convenio Andrés Bello, 2005, pp. 69-92. 
Nacional (www.enlacezapatista.ezln.org.mx) e os www.cacerolazos.com argentinos, ou de reflexão estética de cunho nacionalista como os sites de curta-metragens para a web, como www.tech-mex.mx.org, www.solocortos.com e www.tuminuto.com, do México, ou www.videometraje.com.ar, da Argentina. Nos suportes standards como o cinema de longa-metragem, por exemplo, a herança dos Nuevos Cines Latinoamericanos foi enjeitada tanto do regime de produção como de representação dos filmes.

Segundo Fredric Jameson "the free movement of American movies in the world spells the death knell of national cinema everywhere, perhaps of all national cinemas as distinct species" ${ }^{28}$ Essa situação teve ressonância em quase todos os planos do sistema cinematográfico regional. Na América Latina as medidas tomadas pelos primeiros governos democráticos ao início do decênio de 1990 foram a eliminação dos órgãos estatais que estavam encarregados de apoiar as produções nacionais, tais como Embrafilme no Brasil (1990), e Películas Nacionales e COTSA (1992), de distribuição e exibição no México. Na Argentina foram esses setores os mais atingidos, e as companhias estrangeiras controlam 70\% do setor. Para a produção houve a necessária promoção de canais para parcerias internacionais, como o programa Ibermedia, que fomenta co-produções entre países da América Latina e da península Ibérica, o Sundance Institute e o Hubert Bals Project, com o apoio do Festival de Rotterdam.

Criaram-se várias produtoras independentes na região, como a argentina Patgonik (produziu Nueve Reinas, 2000, e Kamchatka, 2002), a mexicana Altavista (Amores perros, 2000) e a brasileira Videofilms (Cidade de Deus, 2002 e Madame 0Satã, 2002). Na distribuição ocorre uma concentração de multinacionais como Buenas Vista International, Sony Pictures, Miramar Films e 20th Century Fox. É importante comentar que essa reacomodação de forças no sistema cinematográfico da região, segundo Deborah Shaw, faz com que hoje "there are more Latin American films than ever before on secreens in big cities in Europe, the United States [...] There has never been such visibility for films

${ }^{28}$ Jameson, op. cit., p. 65. 
from the region". ${ }^{29}$ Não obstante, o quadro da representação modificou-se sensivelmente. A direção de arte, a fotografia, a montagem e os gêneros delatam a qualificação de Tamara Folicov ${ }^{30}$ a Nueve Reinas (2000) de Fabián Bielinsky, e que consigna a impressão do espectador ao final de El secreto de tus ojos (2009) de Juan José Campanela e vencedor do Oscar de melhor filme estrangeiro em 2010: filme norte-americano falado em espanhol.

Recibido: 30 de octubre, 2010.

Aceptado: 3 de febrero, 2011.

\section{BiBLIOGRAFÍA}

AgulHon, Maurice, Penitentset franc-maçons de l'ancienne Provence: essai sur la sociabilté méridionale, París, Fayard, 1968, 452 pp.

AppaduraI, ARjun, Modernity at Large. Cultural dimensions of globalization, Minneapolis, Minnesota University Press, 1996, 229 pp.

Barthes, Roland, Mitologias, $11^{\mathrm{a}}$ ed., trad. de Rita Buongermino y Pedro de Souza, Río de Janeiro, Bertrand, 1993, 256 pp.

Baudrillard, Jean, Xerox and Infinity, trad. de Agitac, Londres, Touchepas, 1988.

Bella, NúBIA, "Migración, redes sociales y ciudadanía. Aportes para la definicón de políticas migratorias en Colombia, Ecuador y España", en Jesús MartínBarbero, Guillermo Sunkel, Núbia Bello, Nina Pacari, Veja Arce y José Manuel Valenzuela, América Latina. Otras visiones desde la cultura, Bogotá, Convenio Andrés Bello, 2005, 169 pp.

29 Deborah Shaw [ed.], Contemporary Latin American Cinema. Breaking into the Global Market. Lanham, Maryland, Rowman \& Littlefield Publishers, 2007, p. 3.

30 Tamara Folicov, "Argentina's Blockbuster Movies and the Politics of Culture under the Neoliberalism, 1989-1998", en Media, Culture and Society, núms. 22 y 23, 2004, 335 pp. 
Bignell, Jonathan, Postmodern Media Culture, Edinburg, Edinburg University Press, 2000, 241 pp.

CANClini, NÉStor García y Carlos Moneta [coords.], Las industrias culturales en la integración latinoamericana, México, Caracas, Grijalbo/Sistema Económico Latinoamericano, 1999, $342 \mathrm{pp}$.

Castells, Manuel, Communication Power, Oxford, Oxford University Press, 2009, 608 pp.

Cheah, Pheng y Bruce Robbins [orgs.], Cosmopilitics. Thinking and Feeling beyond the Nation, Minneapolis, Minnesota University Press, 1998, 380 pp.

Clifford, James, The Predicament of Culture. Twentieth-Century Ethnography, Literature, and Art, Cambridge, Mass., Londres, Harvard University Press, 1988, 228 pp.

,Itinerarios transculturales, Barcelona, Gedisa, 1999, 496 pp.

Douglas, Mary y Baron Isherwood, The World of Goods. Towards an Antrhopology of Consuption, $2^{a}$ ed., Londres, Nueva York, Routledge, 1996, 327 pp.

Folicov, Tamara L., "Argentina's Blockbuster Movies and the Politics of Culture under the Neoliberalism, 1989-1998", en Media, Culture and Society, núms. 22 y 23, 2004, pp. 327-342.

Grignon, Claude y Jean-Claude Passeron, Lo culto y lo popular. Miserabilismo y populismo en sociología y en literatura, trad. de María Sonderéguer, Buenos Aires, Nueva Visión, 1991, 239 pp.

Guerra, FrançoIs-Xavier, "A nação moderna: nova legitimidade e velhas identidades", en Jancso, Istvan [org.], Formação do Estado e da nação, São Paulo, Hucitec, 2003, pp. 33-60, 703 pp.

Harvey, David, Spaces of Global Capitalism: Towards a Theory of Uneven Geographical Development, Londres, Verso, 2006, 154 pp.

InNIS, HaRold, The Bias of Communication, 8 a ed., Toronto, Toronto University Press, 1999, 226 pp. 
Sebastião Guilherme Albano da Costa • Maria Érica de Oliveira lima

JAmBeiro, OTHON, A tv no Brasil no século XX, Salvador, Universidade Federal da Bahia, 2001, 206 pp.

Jameson, FreDeric, "Notes on Globalization as a Philosophical Issue", en Jameson, Frederic y Masao Miyoshi [eds.], The Cultures of Globalization, Durham, Duke University Press, 1998, 416 pp. ,The Political Unconscious: Narrative as a Socially Symbolic Act, Londres, Methuen, 1981, 320 pp.

LANDI, ÓsCAR, "Campo cultural y democratización en Argentina", en Néstor García Canclini, Políticas culturales en América Latina, México, Grijalbo, 1987, $257 \mathrm{pp}$.

Martín-Barbero, Jesús, "Culturas y nuevas mediaciones tecnológicas", en Jesús Martín-Barbero, Guillermo Sunkel, Martha N. Bello, Nina Pacari Vega y José Manuel Arce Valenzuela, América Latina. Otras visiones desde la cultura, Bogotá, Convenio Andrés Bello, 2005, 169 pp.

MCLuHAN, MarSHAL, Understanding the Media: The extensions of Man, 9a ed., Massachusetts, miт Press, 1994, 392 pp.

Miller, Toby y Richard MaXwell, "Film and Globalization", en Oliver Boyd-Barret [ed.], Communications Media. Globalization and Empire, Eastleigh, Londres, John Libbey Publishing, 2006, 304 pp.

MoReL, MARCO, As transformações dos espaços públicos. Imprensa, atores políticos e sociabilidades na Cidade Imperial (1820-1840), São Paulo, Hucitec, 2005, $326 \mathrm{pp}$.

Ortiz, Renato, Sílvia Borelu y José Ramos, Telenovela. História e produção, São Paulo, Brasiliense, 1991, 253 pp.

Pitman, Thea y Claire Taylor, Latin American Cyberculture and Cyberliteratur, Liverpool, Liverpool University Press, 2007, 256 pp.

Radway, Janice A., Reading the Romance. Women, Patriarchy, and Popular Literature, $2^{a}$ ed., Chapel Hill, Londres, North Carolina The University Press, 1991. 
Ribeiro, Gustavo Lins, Pos-Imperialism. A Latin-American Cosmopolitics, Brasília, Universidade de Brasília, 2005, 16 pp.

RobBins, Bruce, Feeling Global. Internationalism in Distress, Nueva York/Londres, New York University Press, 1999, 236 pp.

SÁNCHEz-Ruiz, EnRIQue, "La industria cinematográfica del TLCAN: del 'mercado libre' a las políticas públicas", en Néstor García Canclini, Ana Mantecón Rosas, Enrique Sánchez-Ruiz [coords.], Situación actual y perspectivas de la industria cinematográfica en México y en el extranjero, Guadalajara, Universidad de Guadalajara/Instituto Mexicano de Cinematografía, 2006, 254 pp.

Shaw, Deborah [ed.], Contemporary Latin American Cinema. Breaking into the Global Market, Lanham, Maryland, Rowman \& Littlefield Publishers, 2007, 201 pp.

Yúdice, GEORGE, "La globalización y la nueva división internacional de trabajo cultural", en Mónica Lacarrieu y Marcelo Álvarez [comps.], La (indi) gestión cultural. Una cartografía de los procesos culturales contemporáneos, Buenos Aires, Ciccus, 2002, 276 pp.

Wallerstein, Immanuel, Modern World-System: Capitalism, Agriculture and the Origins of the European World-Economy in the Sixteenth Century, 2a ed., Nueva York, Academic Press, 1981, 410 pp.

O Universalismo europeu. A retórica do poder, trad. de Beatriz Medina, São Paulo, Boitempo, 2007, 144 pp. 